\title{
Loss to Follow-up: A Deceptive Enigma
}

\author{
Sandeep Patel ${ }^{1} \quad$ Vishal Kumar $^{1} \quad$ Shahnawaz Khan ${ }^{1}$ Amit Salaria ${ }^{1}$
}

1Department of Orthopedics, Post Graduate Institute of Medical Education \& Research, Chandigarh, Punjab, India

\begin{abstract}
Address for correspondence Sandeep Patel, MBBS, MS, DNB, Department of Orthopedics, Post Graduate Institute of Medical Education \& Research, Chandigarh 160012, Punjab, India (e-mail: sandeepdrpatelortho@gmail.com).
\end{abstract}

\begin{abstract}
Keywords

- follow-up

- outcome

- data

- registry
\end{abstract}

\section{Introduction}

Loss to follow-up not only indicates loss of patients but also failure to trace patients. ${ }^{1}$ Significant loss to follow-up can affect the validity of a study. As a result, the impact of study is reduced. The importance of loss to follow-up has been very scarcely and meagerly highlighted in the literature.

More than one-fifth loss to follow-up leads to significant selection bias. ${ }^{2}$ Loss to follow-up not only affects the validity of the study but also affects patient care. In the cohort studies, follow-up rates of 50 to $80 \%$ are accepted by authors. ${ }^{3}$ But, in most of the cases, these recommendations have not been tested. The causes of loss to follow-up may vary from patient's age, occupation, chronicity of the disease, etc. ${ }^{1}$ Meanwhile, it is also not realistic to expect a $100 \%$ follow-up in a study.

\section{Effect of Loss to Follow-up}

Impact on study: More than one-fifth loss to follow-up results in significant bias in reporting results. ${ }^{2}$ Apart from the validity of the study, it also affects the power of the study and its generalizability. ${ }^{4}$ There is also loss of energy, time, manpower, and resources involved to trace the lost participants.

Impact on patient care: The patient may even suffer from adverse effects of treatment. Lack of proper follow-up in such cases can lead to discontinuation of treatment in time or self-continuation of medications, which were supposed to be stopped on time. A patient may lose his life or can suffer from morbid outcomes. In case of communicable diseases, even the near and dear ones of the patient can suffer. Consequently, this also leads to loss of faith in the existing health system among patients and treatment afforded to them.

\section{published online}

May 10, 2021
DOI https://doi.org/

$10.1055 / \mathrm{s}-0041-1728971$ ISSN 0379-038X (c) 2021. National Academy of Medical Sciences (India).

This is an open access article published by Thieme under the terms of the Creative Commons Attribution-NonDerivative-NonCommercial-License, permitting copying and reproduction so long as the original work is given appropriate credit. Contents may not be used for commercial purposes, or adapted, remixed, transformed or built upon. (https://creativecommons.org/licenses/by-nc-nd/4.0/).

Thieme Medical and Scientific Publishers Pvt. Ltd. A-12, 2nd Floor, Sector 2, Noida-201301 UP, India 


\section{Causes for Loss to Follow-up in India}

In India, majority of the patients are lost to follow-up, due to high levels of illiteracy and lack of awareness regarding health concerns and issues. Poverty being an important reason for the above. Most of the patients do not follow-up, because they do not have enough money to come to a health center repeatedly, while some do not have enough money to continue treatment, and continuing treatment becomes a financial burden. Heavy patient load and long queues at hospitals also prove to be detrimental in follow-up of the patients. While the number of tertiary care and specialty centers is limited and are located only in big cities of the country, these centers attract patients from all over the state. The rest of health care delivery centers are not specialized or advanced enough to cater to the needs of the population. The other reason that physicians feel is that the lack of follow-up is due to restoration of well-being of the patient. There is no specific provision made by hospitals to keep a track of their patients. Hospital information system is still in its infancy in a developing country like India, where only big centers have implemented it. Another reason for loss to follow-up in India is easy accessibility to quacks and alternate forms of medicine.

\section{Search Methods}

\section{Inclusion criteria}

1. Studies which revealed loss to follow-up.

2. Studies which reported outcomes of loss to follow-up.

We conducted a literature search on PubMed using the keywords mentioned in - Table $\mathbf{1}$.

\section{Discussion}

There are three mechanisms of loss to follow-up as described in prospective studies:

i. Missing at random (MAR).

ii. Missing completely at random (MCAR).

iii. Missing not at random (MNAR). ${ }^{5}$

Missing at random (MAR) means there is a systematic relationship between missing values and observed data. The probability of subject remaining in a study depends on exposure and confounder but not the outcome. ${ }^{3}$ On the other hand, loss to follow-up by MCAR mechanism means there is no relationship between missing data and observed data. The missing data are a random subset of data. Loss to follow-up by MNAR mechanism means there is a relation between missing

Table 1 Search methodology

\begin{tabular}{|l|l|}
\hline PubMed database & No. of hits \\
\hline Loss to follow-up & 82,254 \\
\hline Outcomes of loss to follow-up & 17,743 \\
\hline Loss to follow-up in research & 29,867 \\
\hline Loss to follow-up in India & 2,049 \\
\hline
\end{tabular}

data and observed outcome. So, in a cohort study, MNAR mechanism cannot be ignored, as it affects the outcome. ${ }^{3}$

Akl et al conducted a web-based systematic review on 235 studies and found that loss to follow-up was not reported in $13 \%$ of the studies. ${ }^{6}$ Rest of the studies reported median loss to follow-up of $6 \%$. As much as $66 \%$ of studies used survival analysis to determine loss to follow-up.

Swaminathan et al highlighted the importance of active follow-up in cancer patients in India. ${ }^{7}$ They suggested that active follow-up improved 5-year survival rates in cancer patients by $41 \%$.

Murray et al performed a survival analysis on total hip arthroplasty patients and found that the patients who did not follow-up had worse outcomes as compared with the ones who followed regularly. ${ }^{8}$ They also found that the cumulative rate of loss to follow-up increased over years. The patients lost to follow-up group had more adverse outcomes as compared with the ones who followed-up at regular intervals. This loss to follow-up could have been due to the deaths or the patient visited some other doctor due to poor outcome.

Baron et al reported that more than $20 \%$ of data was missing in one-third of the articles on superiority trials assessing structural outcomes in rheumatic diseases. ${ }^{9}$ They also noticed violation of intent to treat principle, which should have been applied in such studies. This questions the outcomes of such studies.

Somerson et al conducted a systematic review of randomized controlled trials in orthopedic trauma and found that loss to follow-up was not reported in one-fifth of the studies and mean loss to follow-up was found to be $10.4 \% .{ }^{10}$ They also found that studies with shorter follow-up duration had less loss to follow-up of patients.

Zelle et al found that the level of significant loss to follow-up varied from $15 \%$ to $75 \%{ }^{11}$ They also found that males, smokers, drug abusers, and uninsured patients were more likely to get lost to follow-up. They further opined that social deprivation is the main reason for noncompliance.

Solberg et al followed their spine surgery patients and found that there were no statistically significant differences in outcomes of those who followed-up on regular basis and those who were noncompliant in their follow up. ${ }^{12}$

Zunzunegui et al conducted a study on aging population and found that at the end of 4 years, $48 \%$ of the subjects were lost to follow-up. ${ }^{13}$

\section{Suggestions to Improve Loss to Follow-up}

Many ways have been suggested by many authors on how to reduce loss to follow-up. ${ }^{14}$ In a developing country like India, health education is of prime importance. The health care delivery system needs to be equipped and strengthened, so as to meet the needs of the people at primary level. This will reduce the burden on the tertiary care units in the country and limit long queues. Prior appointments should be taken to minimize last moment rush. Hospital information system should be implemented in all hospitals, be it primary health center or a tertiary care center. A central disease-based registry is an envisaged and viable option. This will help not only in reducing loss to follow-up but also provide us trends of the 
diseases. Wherever possible active follow-up should be done, particularly in cases of communicable diseases. Patients should be informed about various government schemes and health insurance policies, which would benefit them in getting treatment in case of chronic diseases. Small incentives can be given to patients just to encourage follow-up. Even social media can play an important role in this issue. Patients can be informed about their possible follow-up through messages on cell phones. A system of reverse reference, that is, referring the patients back to the referring doctor for further follow-up can and has to be introduced. In a study, it was found that the use of electronic media reduces loss to follow-up by $80 \% .{ }^{15}$ Local health care workers need to be more active in hard-to-reach areas. Involvement of local community will also help us trace and follow the noncompliant patients. The patients who travel long distances can be referred back to local physicians to minimize loss to follow-up.

A system of reverse referrals, that is, referring the patient back to referring physician may also contribute to reduce possibility of lost to follow up.

We can minimize loss to follow-up by strictly adhering to the study protocols. Making the participants understand the nature and outcomes of the study becomes important. The participants should be followed-up at short and regular intervals. A pilot study should always be conducted before any study to assess its feasibility, outcome, and impact.

\section{Conclusion}

Loss to follow-up needs to be reported in all prospective studies. This will help us not only to assess the validity of study but also provide us scope for further research. It will also reflect the effect of the intervention used in the study. Minimizing loss to follow-up also benefits in patient care and improves the outcome of treatment method adopted. The results of a study also become reliable if there is minimum loss to follow-up. We can also determine actual survival rates in fatal diseases. The course of a disease can also be monitored, and appropriate intervention can be done at appropriate points in time to prevent morbidity and mortality.

\section{Author Contributions}

V. K.: gave the idea and concept and corrected the manuscript; S.P.: came up with the idea, helped in writing, gathered references, and carried out proofreading; S.K.: wrote the manuscript; A.S.: corrected the manuscript.

\section{Conflict of Interest}

None declared.

\section{References}

1 Small WP. Lost to follow-up. Lancet 1967;1(7497):997-999

2 Dettori JR. Loss to follow-up. Evid Based Spine Care J 2011; 2(1):7-10

3 Kristman V, Manno M, Côté P. Loss to follow-up in cohort studies: how much is too much? Eur J Epidemiol 2004;19(8):751-760

4 Fewtrell MS, Kennedy K, Singhal A, et al. How much loss to follow-up is acceptable in long-term randomised trials and prospective studies? Arch Dis Child 2008;93(6):458-461

5 Little RJA, Rubin DB. Statistical Analysis with Missing Data. New York: John Wiley \& Sons; 1987

6 Akl EA, Briel M, You JJ, et al. Potential impact on estimated treatment effects of information lost to follow-up in randomised controlled trials (LOST-IT): systematic review. BMJ 2012;344:e2809

7 Swaminathan R, Rama R, Shanta V. Lack of active follow-up of cancer patients in Chennai, India: implications for population-based survival estimates. Bull World Health Organ 2008;86(7):509-515

8 Murray DW, Britton AR, Bulstrode CJK. Loss to follow-up matters. J Bone Joint Surg Br 1997;79(2):254-257

9 Baron G, Boutron I, Giraudeau B, Ravaud P. Violation of the intent-to-treat principle and rate of missing data in superiority trials assessing structural outcomes in rheumatic diseases. Arthritis Rheum 2005;52(6):1858-1865

10 Somerson JS, Bartush KC, Shroff JB, Bhandari M, Zelle BA. Loss to follow-up in orthopaedic clinical trials: a systematic review. Int Orthop 2016;40(11):2213-2219

11 Zelle BA, Buttacavoli FA, Shroff JB, Stirton JB. Loss of follow-up in orthopaedic trauma: who is getting lost to follow-up? J Orthop Trauma 2015;29(11):510-515

12 Solberg TK, Sørlie A, Sjaavik K, Nygaard ØP, Ingebrigtsen T. Would loss to follow-up bias the outcome evaluation of patients operated for degenerative disorders of the lumbar spine? Acta Orthop 2011;82(1):56-63

13 Zunzunegui MV, Béland F, Gutiérrez-Cuadra P. Loss to follow-up in a longitudinal study on aging in Spain. J Clin Epidemiol 2001;54(5):501-510

14 Sprague S, Leece P, Bhandari M, Tornetta P, III, Schemitsch E, Swiontkowski MF. S.P.R.I.N.T. Investigators. Limiting loss to follow-up in a multicenter randomized trial in orthopedic surgery. Control Clin Trials 2003;24(6):719-725

15 Mehta KG, Baxi R, Patel S, Parmar M. Drug adherence rate and loss to follow-up among people living with HIV/AIDS attending an ART centre in a tertiary government hospital in western India. J Family Med Prim Care 2016;5(2):266-269 